\title{
Approaches to the Teaching of Grammar: Methods and Strategies
}

\author{
*Arm Mahbuber Rahman ${ }^{1}$, Md. Sumon Ahmed ${ }^{1}$ \\ ${ }^{1}$ Department of English, Khwaja Yunus Ali University, Sirajgonj, Bangladesh
}

\begin{abstract}
Every language has its grammar. Whether it is one's own mother tongue or second - language that one is learning. The grammar of the language is important. This is because acceptability and intelligibility, both in speech and in writing within as well as outside one's own circle or group depend on the currently followed basic notions and norms of grammaticality. A knowledge of grammar is perhaps more important to a secondlanguage learner than to a native speaker has intuitively internalized the grammar of the language whereas the second - language learner has to make a conscious effect to master those aspects of the language which account for grammaticality. It is, therefore, necessary for us, to whom English is a second - language, to learn the grammar of the language. So, without the knowledge of the grammar of a particular language, we cannot properly use the language in communication. But question may arise what should be the method and approach to the study of grammar. Several approaches have been followed through the ages for the study of English grammar. The major approaches are the traditional approach, the structural approach, the notional-functional approach and the communicative approach.
\end{abstract}

Keywords: English grammar, language, communication, approach

\section{Traditional Approach}

Language has been studied for centuries in ancient Greece, Rome, Arab, India etc. The word 'traditional' is usually used to refer to the rendition of language study and writing grammars which was handed down to us from ancient Greeks. Through Rome and then, after Renaissance, through other European languages which generally followed the Greek and Roman tradition. Traditional grammar also does not refer to any single author's or country's work. It was not as if a uniform, or identical grammars were written or taught at that time. It refers to the general attitude of scholars of the time, to their specific methodology, their ways of looking at things. For example, the ideas about sentence and sentence analysis came from Aristotle and Plato ( $5^{\text {th }}$ century B.C.): The stoic grammars had written parts of speech, the scholastic philosophers of the middle Ages had speculated about meaning, the concept of 'correctness' came from the latter, eighteenth century grammarians of England had ideas about the history of language deriving from the nineteenth century emphasis on comparative philology.

Before the eighteenth century the study of the English language was neglected. Preference was given to the classical languages such as Greek and Latin was the language of the church and of the university and was widely used by the educated person throughout Europe. By the eighteenth century, however, the knowledge of the Renaissance had been translated into the language which everybody spoke. This gradual use of English for affairs of state and literature and the invention of the printing press generated a need for the study of grammar. The scholar should want to codify what they felt was a disorderly language.

These scholars believed in universal grammar- a perfect grammar of which individual grammar was corruptions. (This belier in a universal grammar exists even today; this is because some grammatical features are shared by all languages). Because the educated Englishmen of the $18^{\text {th }}$ century knew Latin so well that they naturally believed that that this classical language must be the closest to the universal grammar. The differences between English and Latin they considered as errors or corruptions of English. The grammar text books of period, then were written to correct these errors and to prescribe desirable usage. As Johnson says in the preface to his dictionary: 
"I have laboured to refine our language to grammatical purity, and to clear it from colloquial barbarism, licentious idioms, and irregular combinations".

In order to establish a language as perfect, early grammarians obviously had to use Latin as a model to build as English grammar. Their difficulties were great, however, Latin and English differ significantly from one another. In Latin morphology (word from) is far more important than syntax (word order). In English, syntax is more important than morphology. It is true that we alter word form English too; 'run' is changed into 'ran' or 'drive' into 'drives'. But we can understand an English sentence in which the usual form changes are not made; for example, there is no difficulty in understanding the sentences, "The engine of the car run well when he drives the car fast". The intended meaning of the sentence will not be grasped by us if our understanding depends primarily upon word form. As it is, however, it makes sense though it sounds awkward.

What is essential to our understanding of English is syntax or word order. The sentence "Engine well runs the fast car of the drives the car he fast when" is unintelligible because its order is simple not common to the English language system. In Latin nearly the opposite is true. The form of most Latin words is more important than their position.

Generally, the failure to alter the form of Latin words results in confusion. But except for a few like 'ad' and 'cum', most Latin word do not have fixed places within a sentence.

More problems appeared when the grammarians attempted to analyse English structures in two ways - some in terms of lexical meaning and others in terms of grammatical function.

The most widely known definition of the sentence is based upon meaning:

"A sentence is a group of word expressing a complete thought" But what exactly is a thought? And if we could define it how would we determine its completeness?

Another popular definition is functional: "A sentence must have a subject which names a person, place, thing or idea, and a predicate which says something about the subject". This explains a construction like "The child is crying". But couldn't "the crying child" also fit the definition? The word 'child' names a person; and the word 'crying' says the something about the child.

For traditional grammarians, written language was both the aim and the basis of their work. There are few or no rules for teaching spoken language. Spoken language is generally neglected. Pronunciation and suprasegmental feature find no mention in these grammars. The learners where asked to cram by note memory rules of grammar and translate the language into the mother tongue or vice-versa. Where used to be composition exercise, but no attention was paid to oral practice. The traditional grammar included rules and even vocabulary that may be more characteristic of written English. The rule for example, phonetic. Morphology, syntax and semantics, But traditional grammarians, discussed with phonetics, phonemics, morphology and syntax. In this way we can see that the structured grammar which deals with one more topic which is known a semantics.

\section{Structural APPRoACH}

One of the primary characteristics of structural grammar is its division of the study of the language into basic parts: structure and meaning. Usually, the structural grammar prefers to study the grammatical forms or structures of the language before considering lexical meaning.

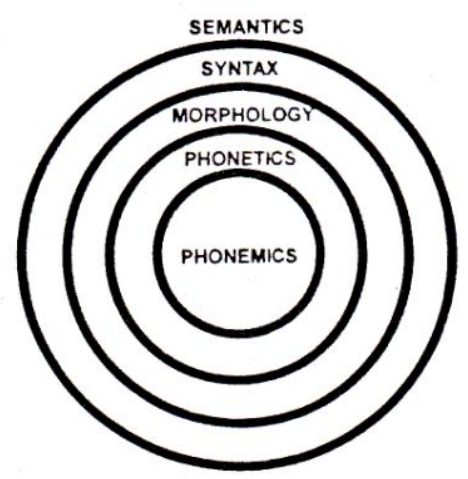

Diagram1. Structural Grammar 
English grammar in terms of structure is not as complicated as it seems. The native speakers remember learning lexical meanings because this takes place every time they encounter a new word. They do not learn grammatical signals because this happens early and informally in their lives. But the second language learner is not in the same position as the native speaker is. His internalization of grammatical to the structures though not complicated is through deliberate exposure to the language. That is why; he has to learn both lexical meanings and grammatical signals more or less at the same time.

\section{NOTIONAL -FUNCTIONAL}

The term "functional-notional approach" embraces any strategy of language teaching that derives the content of learning from an initial analysis of the learner's need to express three different kinds of meaning: Functional (i.e. the social purpose of the utterance); Modal (the degree of likelihood); Conceptual - the meaning relations expressed by forms within the sentence (categories of communicative function). These method of language teaching is categorize along with others under the rubric of a communicative approach. The method stresses a means of organizing a language syllabus. The emphasis is on breaking down the global concept of language into units of analysis in terms of communicative situations in which they are used.

Notions are meaning elements that may be expressed through nouns, pronouns, verbs, prepositions, conjunctions, adjectives or adverbs. A notion is a concept, or idea: it may be quite specific, in which case it is virtually the same as vocabulary (dog, house, for example); or it may be very general - time, size, emotion, movement - in which case it often overlaps with the concept of "topics". A notion may be "time past"; this may include past tenses, phrases like a month ago, in 1990, last week, and utterances using temporal clauses beginning with when ....., before...., after.... and so on;

A function is some kind of communicative act: it is the use of language to achieve a purpose, usually involving interaction at least between two people. Examples would be suggesting, promising, apologizing, greeting, inviting.

"Inviting" may include phrases like "Would you like to....? I suggest..., How about...? Please...

\section{Strategies of Teaching Grammar}

The strategies of teaching grammar depend on certain key areas of focus. These areas may be identified with reference to the practice and use of grammar.

\begin{tabular}{|c|c|}
\hline Practices & Use \\
\hline Drill & \multirow{2}{*}{ Communicative } \\
\hline Contextualized clues & \\
\hline Communicative & \\
\hline
\end{tabular}

\subsection{Practice: Drill}

Drills can be of the following types:

Substitution Tables

\begin{tabular}{|c|c|c|}
\hline He & \multirow{3}{*}{$\begin{array}{c}\text { had } \\
\text { ate }\end{array}$} & $\begin{array}{c}\text { an apple } \\
\text { a bar of chocolate } \\
\text { two ice creams }\end{array}$ \\
\cline { 1 - 1 } She & & \\
\hline Raja & \\
\hline
\end{tabular}

Structure Tables

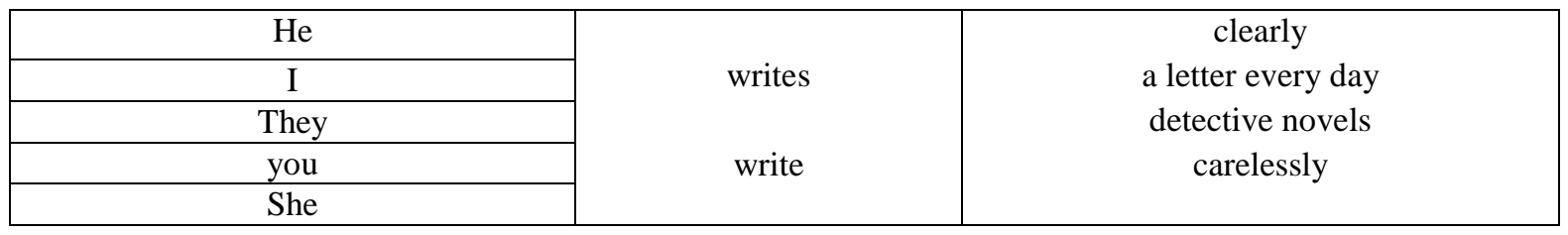




\section{Cue/Response}
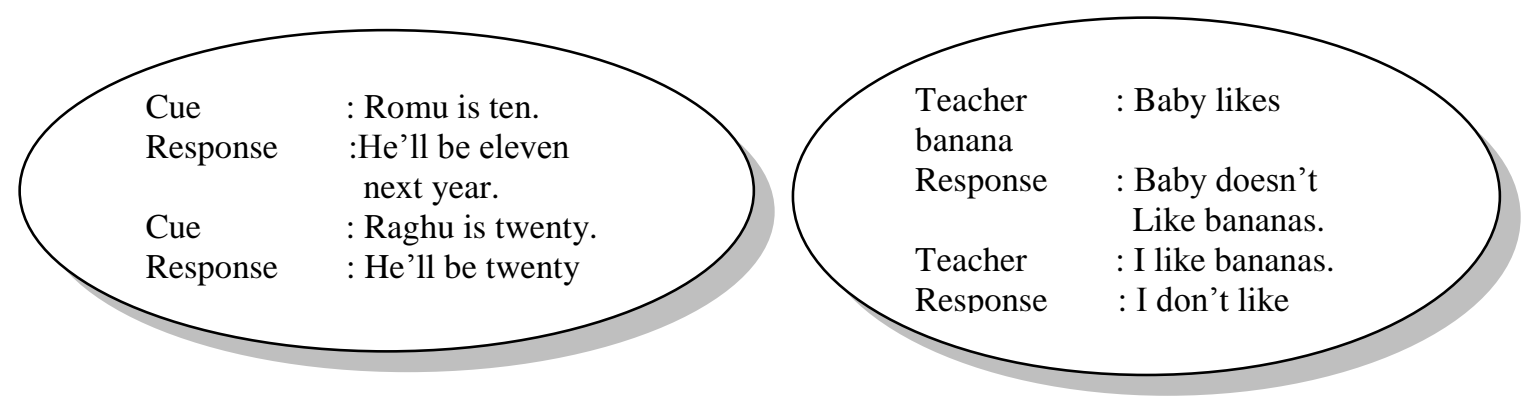

\subsection{Practice: Contextualized Clues}

In this type of an exercise the context provides the clue to the type of grammatical item to be used.

\subsubsection{Now Response to the Following Situations}

The washing is outside and it starts to rain.

Your father cannot understand a letter written in English.

Your friend in says he's thirsty.

\subsubsection{Response to the Given Situations}

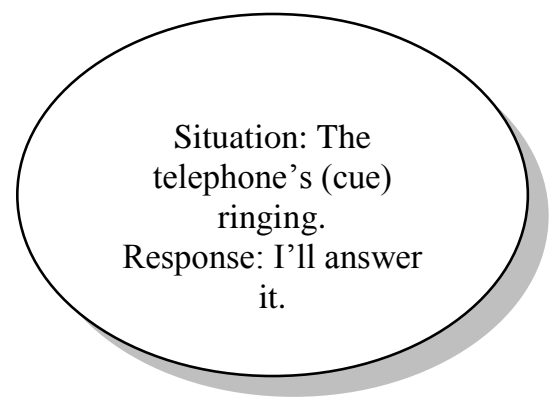

A friend has come to see you in your house. Offer him something to drink.

You are in a post office. You need three stamps for a letter to the USA. What do you say?

\subsubsection{Passages/Letter Completion}

Complete the following letter using verbs in either the simple present or the present progressive

Dear Bhanu,

We (enjoy) our holiday a lot. Every day, we (walk) down to the beach, (take) a dip the sea; (have) lunch at Tropicana.

In fact, I (write) the letter from Tropicana. We (wish) you were here.

Love

\section{Lata}

\subsection{Practice: Communicative}

Here, the grammar to be practiced is based on information -gap or opinion - gap activities. The general framework is given, but the language is not controlled strictly.

\subsection{Communicative Question - Asking Activity}

Through fifteen yes/no questions, learners try to discover the person, animal or thing a learner can take the oral of the teacher.

Learner 1 : Are you alive?

Teacher : No. 


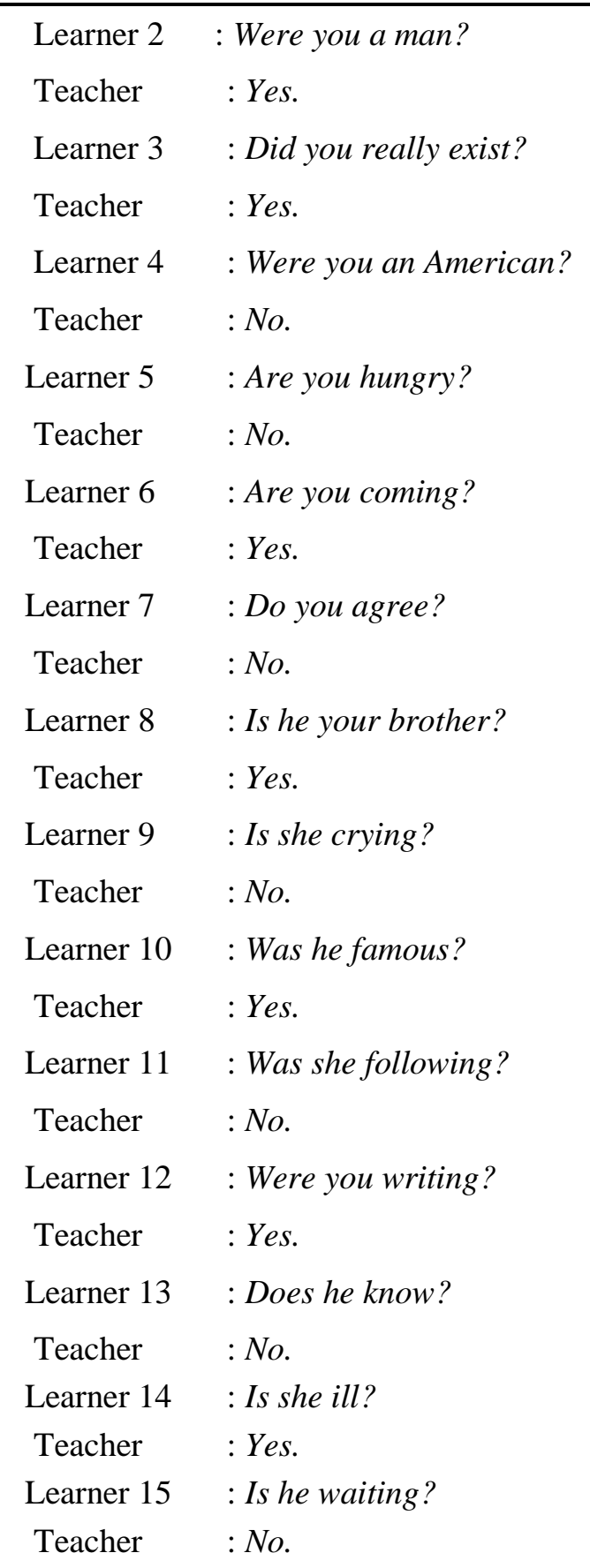

\section{Evaluating Grammar TechniQues}

Grammar is a heavy subject. If we ask most teachers how they fell about it they respond with words like 'boring' or 'difficult' and they recount stories of student who ask for 'more grammar' with amused resignation. Grammar with amused evil, without the high status afforded to other elements in he curriculum such as communicative activities, reading, the use of videos and computers, etc.

Grammar has had a chequered history in the evolving word of EFL teaching and learning. There was a time, of course, when the study of grammar and techniques of translation were the main approaches to language learning. The Direct Method changed all that, however, and Audio- Lingualism (and structural-situational methodology) made strenuous effect to disguise the grammar that was, in fact, being taught.

Grammar's decline continued in the first flowering of the Communicative Approach, concerned it seemed to be with functional teaching and unstructured (in the linguistic sense) spontaneous communicative. But gradually the communicative movement has provoked a debate about exactly where grammar fits into the curriculum and the results of this discussion are now beginning to emerge as a renewed interest in, and emphasis on, the teaching and study of grammar in the general EFL classroom. 
In order to find out how teachers felt about various styles of grammar teaching a number workshops were help in which teachers (and in least one case, student) were asked to assess a number or activities (see below) in terms of where they fitted on lines between covert and over; student - centred and teacher-centred; creative and non-creative and finally helpful and unhelpful. What exactly do these terms mean in this context?

\section{Conclusion}

Amid the plethora of differed approaches, theories, grammar debates and discussions on the usefulness or otherwise of the teaching grammar what should be the standpoint of a teacher of English? Certainly he cannot do without grammar. Grammar is essential to second-language learning. As Wilkins observes:

"The acquisition of the grammatical system of a language remains a most important element in language learning. The grammar is the means through which linguistic creativity is ultimately achieved and an inadequate knowledge of the grammar would lead to serious limitations on the creativity for communication. A notional syllabus, no less than a grammatical syllabus, must seek to ensure that the grammatical system is property assimilated by the learner".

What Wilkins means is that grammar should be taught; without knowledge of the grammar of the language, one's learning of the language is inadequate; conscious learning of grammar is slowly converted into an automatic process.

Once it is recognized that the teaching a grammar is necessary but the question arises: how is it to be taught? In spite of the disagreements which exist between linguists regarding the relationship of traditional, structural, notional-functional and communicative approaches. Some predict an eventual synthesis of all these approaches to the study of languages. Each approach has made valuable contribution to our knowledge of language and each has assimilated some of the facts and methods of the one preceding it. So we should be eclectic in our approach; we should be select is best suited for our purpose in the classroom. We need not have a whole hearted commitment to traditional grammar; nor should we reject outright the insights of modern linguists. We should select what is the best in these approaches suited to the study of grammar. We should explain and describe grammatical aspects of structure illustrate them with examples and lay down certain rules for our students' guidance and practice. In other words, we should have our own approach based on a synthesis of the insights we have gained from our study of the different approaches to the teaching of grammar.

\section{REFERENCES}

[1] Bright, J.A. \& Macgregor, G.P. (1970).Teaching English as a second language. Longman, London.

[2] Dubin, F. and Olshtain, E. (1991).Course design, development programmes and materials for language learning .Canbirdge University press, New York.

[3] Gurrey, P. (1996).Teaching English grammar. Longmans, London.

[4] Kohli, A.L. (1997).Techniques of teaching English.

[5] Dhankat Rai and Loyons J, (J.1971). An Introduction to theoretical lainguistics. Canbirdge: Canbirdge University Press.

[6] Nagraj, G. (1996). English language teaching approaches methods techniques.

[7] Palmer, F.R. (1990). Grammar. Penguin Books.

[8]Penny, Ur. (1993). Grammar practice activities - A practical guide for Teacher. Cambridge: Cambridge University press.

[9] Rajimwale, S. (1997). Elements of General Linguistics. Vol-1, Rama Brothers, New Delhi.

[10] Robins, R.H (1985). General Linguistics- An Introductory Survey. Longman. London.

[11] Rodriguez. R. and Ortega, R. Anglo American Studies. Vol. Villl, No. 1. April. 1998.

[12] Verghese, C. P. (1998). Teaching English as a Second Language. Sterling Publishers, New Delhi.

[13] Harmer, J. (2007). The practice of English language teaching (4th Edition). Harlow: Pearson.

[14] James, C. (1998). Errors in language learning and use: Exploring error analysis. London:

[15] Addison Wesley Longman. Salem, I. (2007). The lexico-grammatical continuum viewed through student error. ELT Journal 61/3: 211-219. Singleton, D. (2000). Language and the lexicon. London: Arnold. 
[16] Carter, R., \& Nunan, D. (2001). The Cambridge guide to teaching English to speakers of other languages. Cambridge: Cambridge University Press.

[17] Craik, F.I.M., \& Lockhart. R.S. (1972). Levels of processing: A framework for memory research. Journal of Verbal Learning and Verbal Behavior, 11, 671-684.

[18] Doughty, C., \& Varela, E. (2002). Communicative focus on form. In C.

[19] Doughty \& J. Williams (Eds.). Focus on form in classroom second language acquisition (pp.114138). Cambridge: Cambridge University Press.

[20] Doughty, C., \& Williams, J. (2002). Pedagogical choices in focus on form.

[21] Ellis, R. (2002). The place of grammar instruction in the second/foreign language curriculum.

[22] Wang, S. (2010). The significance of English grammar to middle school students in China. Journal of Language Teaching and Research, 1 (3), 313-319

\section{AUTHORS' BIOGRAPHY}

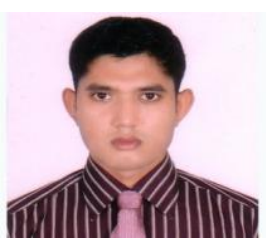

ARM Mahbuber Rahman, is a senior lecturer of English at KhwajaYunus Ali University in Bangladesh. He received his B.A \&M.A degree in English from Aligarh Muslim University, India. His publications are 'Students Attitudes towards English: The Case of Life Science School of Khulna University' (2012), 'English Teaching and Learning in the primary Levels in Sirajgonj' (2016).His research interests include English language Teaching, sociolinguistics, SLA.

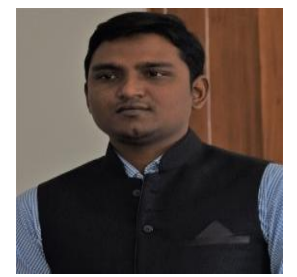

Md Sumon Ahmed, is a senior lecturer of English at KhwajaYunus Ali University in Bangladesh. He received his B.A \&M.A degree in English from Northern University Bangladesh.His publication is 'English Teaching and Learning in the primary Levels in Sirajgonj' (2016). His research interests include English language Teaching, sociolinguistics, SLA. 